\title{
THE PRO-AM OBSERVATORY
}

\author{
F. Espartero ${ }^{1,3}$, M. Frías ${ }^{1,2}$, G. Martínez ${ }^{3}$, and A. Pérez ${ }^{4}$
}

\begin{abstract}
A new model of astronomical observatory is presented, small and versatile, capable of satisfying the demands of professional and amateur astronomers: The PROAM Observatory.

An auto-installing, low cost and easy to transport observatory has been designed, with light and resistant materials. It can house astronomical material, and auxiliary equipment in a reliable and safe way. It has a specific software, that allows us to control the observatory and to operate with all the equipment in remote or in automatic form.
\end{abstract}

\section{RESUMEN}

Se presenta un nuevo modelo de observatorio astronómico, pequeño y versátil, capaz de satisfacer las demandas de astrónomos profesionales y amateur: El Observatorio PROAM.

Se ha diseñado un observatorio low cost auto-montable y de fácil transporte, con materiales ligeros y resistentes. Puede albergar material astronómico, y equipamiento auxiliar de una forma fiable y segura. Dispone de un software específico, que permite controlar el observatorio y operar con todos los equipos en forma remota o en automático.

Key Words: telescopes

\section{INTRODUCTION}

In recent decades we have witnessed a significant increase in the proliferation of astronomical observatories for amateur astronomers and for professional astronomers in different projects requiring small telescopes (Castro-Tirado 2010). Most of these projects were designed with the incorporation of automated domes in different metallic materials, polyester and other light elements (Espartero 2013).

From the point of view of amateur astronomy and the different associations that bring together this large group, the price of the observatory has always been a problem, which has sometimes led to the construction of observatories with scarce and manual means.

In recent years we have witnessed a very important advance in the development of new optical and control equipment, increasingly accurate and at a less exclusive price. This has allowed not only amateur astronomer access to more advanced and almost professional instrumentation, but also encour-

\footnotetext{
${ }^{1}$ Observatorio Andaluz de Astronomía, 23688 La Pedriza, Alcalá la Real, Jaén, Spain (espartero@astroalcala.es).

${ }^{2}$ School of Physics, University of Bristol, BS8 1 TL Bristol, United Kingdom.

${ }^{3}$ Departamento de Ingeniería de la Construcción y Proyectos de Ingeniería. Campus de Fuentenueva, Universidad de Granada, 18071 Granada, Spain.

${ }^{4}$ Departamento de Arquitectura y Tecnología de Sistemas Informáticos, Escuela Técnica Superior de Ingenieros Informáticos, Universidad Politécnica de Madrid.
}

aged the professional collective to develop projects that needed a larger number of telescopes in different locations, such as projects BOOTES (CastroTirado et al. 2008) and GLORIA (Castro-Tirado et al. 2014).

An attempt has beeen made here to contribute to these advances in the development of new techniques and equipment (increasingly more affordable, economical and reliable) with the design of a versatile and complete observatory, which meets the needs of an increasingly modern, ambitious and demanding hobby and profession.

\section{EQUIPMENT}

Two PROAM models have been designed (Figure 1) to solve different needs. Both are built with the materials listed below. All the elements that make up the observatory are mounted/disassembled using screws and their low weight and dimensions allow them to be transported in a light commercial vehicle (Table 1).

- Structure: It is formed by a white lacquered aluminum structure, designed so that the four sides, made of $30 \mathrm{~mm}$ thick sandwich sheet, access door and cover, fit perfectly with screws.

- Side panels: Sandwich plate panel, formed by a layer of polyurethane (PUR) with high capacity of thermal insulation coated by two plates of ribbed steel and pre-lacquered exterior. 
TABLE 1

DIMENSIONS AND WEIGHTS OF THE TWO PROAM MODELS

\begin{tabular}{lccc}
\hline Model & Weight & $\begin{array}{c}\text { Closed } \\
\text { Dimensions }(\mathrm{m})^{*}\end{array}$ & $\begin{array}{c}\text { Open } \\
\text { Dimensions }(\mathrm{m})^{*}\end{array}$ \\
\hline ProAm 2 & 250 & $2 \times 2 \times 1.8$ & $2 \times 4 \times 1.8$ \\
\hline ProAm 3 & 400 & $3 \times 3 \times 2.2$ & $3 \times 6 \times 2.2$ \\
\hline
\end{tabular}

${ }^{*}$ Width $\times$ length $\times$ height.

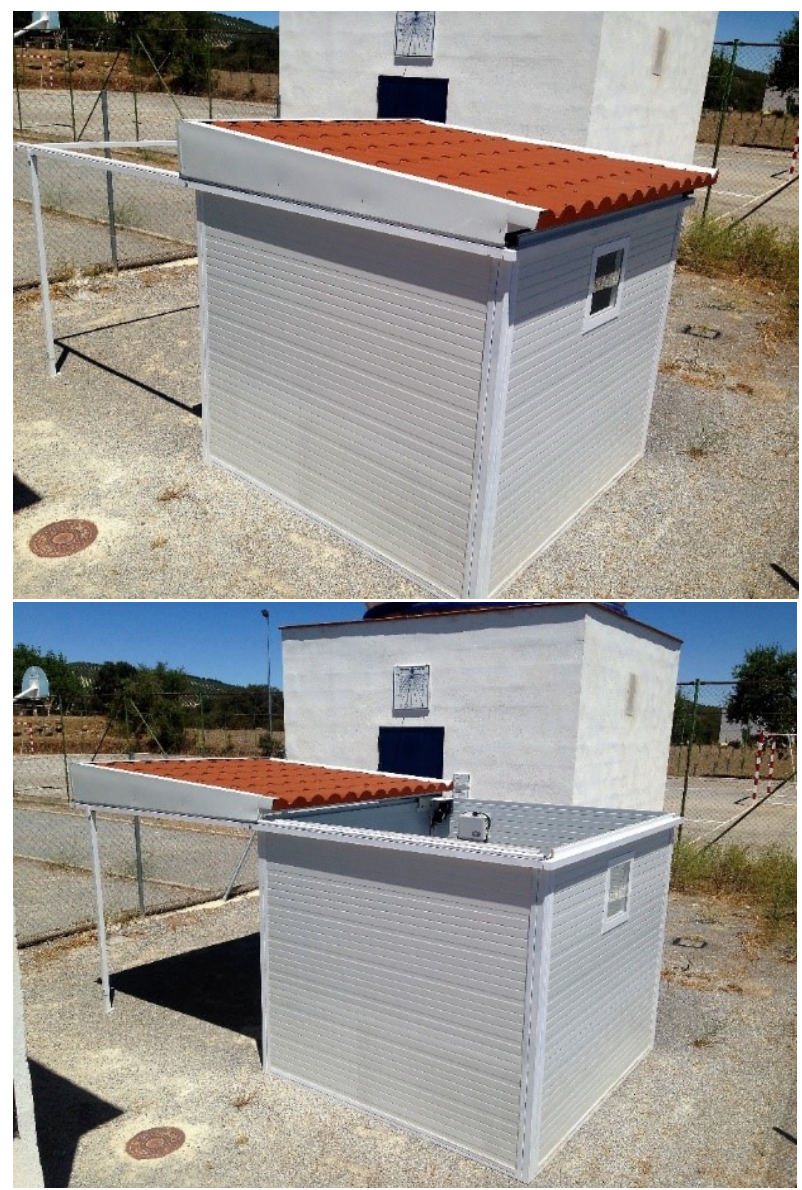

Fig. 1. PROAM Observatory in open/closed positions

- Cover: Cover panel with an imitation roof tile and insulation core made of high density PUR or PIR foam, about $40 \mathrm{~kg} / \mathrm{m}^{3}$. It is a laminated sandwich panel with high mechanical resistance and high thermal insulation. The panel has a thickness of 40 $\mathrm{mm}$ and has specific coating and sealing.

All elements comply with the legal regulations on fire resistance UNE-EN 14509: 2014.

It has access door with standard measures, made of lacquered aluminum with safety lock.

- Electrical system and movement: The electrical

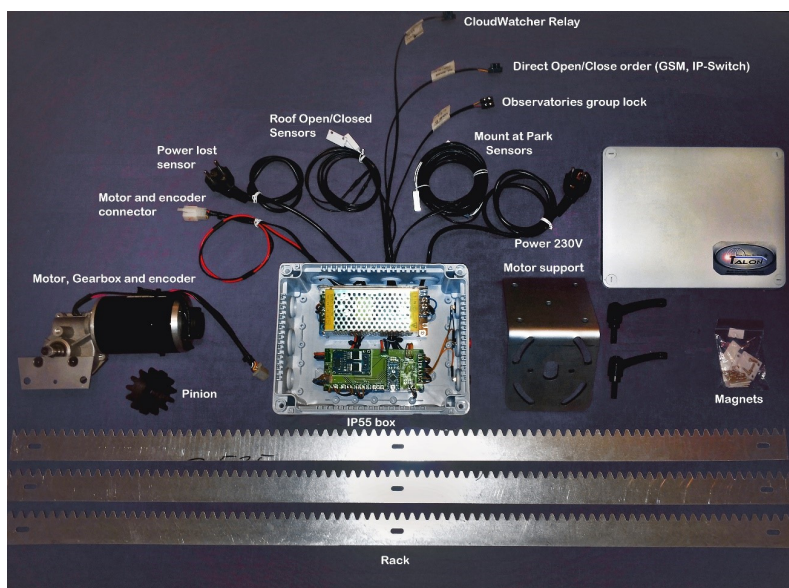

Fig. 2. Detailed electric motor, mechanical movement devices and electronic control.

system connects directly to the domestic power grid at $200 \mathrm{v}$ and has a current transformer to adapt the supply to $24 / 12 \mathrm{v}$. The pinion of the electric motor acts by means of direct attack on the sliding guides of galvanized sheet that move the roof on its rails and according to the opening/closing direction (Figures 2 and 3$)$.

At the end and beginning of the guide, magnetic devices that act as limit switches are placed.

\section{CONTROL SOFTWARE}

A new TALON 6 specific software has been developed under ASCOM protocol to control the ProAm observatory (open / closed), Telescope mount (A.R./Dec.) and other possible additional sensors (weather station, clouds, ...).

TALON6 moves the motors silently (microprocessor controlled), accelerating smoothly to maximum speed and maintaining it until it has to be decelerated to stop smoothly at the destination point. The condition of the roof is continuously reported:

- Open (magnetic sensor limit switch).

- Closed (magnetic sensor limit switch).

- Parked mount (magnetic sensors).

- Ceiling position (exact percentage by encoder).

- Last action taken.

- Current status of the sensors and switches displayed by the light signals on the main screen of the driver.

It continuously monitors the following safety conditions and switches, showing their status in the driver window as color LEDs:

- Loss of communication with the PC.

- Loss of Internet communications.

- CloudWatcher Relay, Cloud Sensor, etc. 


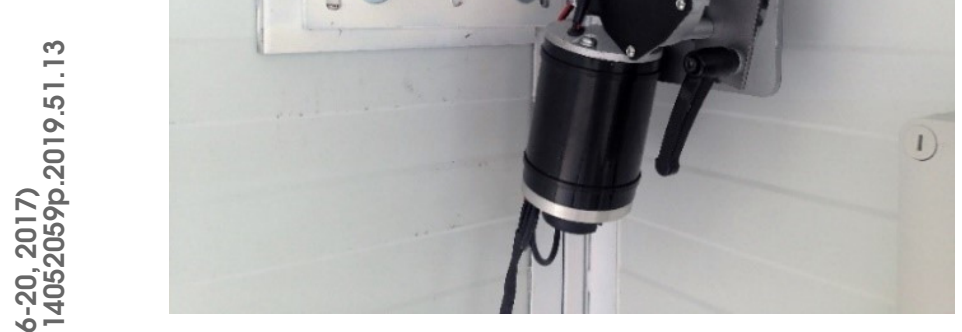

Fig. 3. Detailed installation of motor, clutch, encoder and chain of displacement.

- 230V power loss (before UPS, Uninterruptible Power Supply).

- Countdown to a scheduled stop.

It can also react safely to any of these eventualities by ordering the parking of the mount and the closing of the roof. When one or more closing conditions are activated, a countdown bar indicating the closest closure condition and the remaining time for it appears at the bottom of the interface window.

It monitors (showing its status) the control inputs:

- External keyboard with three buttons, OPEN, STOP and CLOSE.

- MGM input to lock and unlock the system for a group of observatories, parks all the telescopes before closing.

- COM Input, which allows to open and close the ceiling directly using a GSM or IP relay.

Additional features:

- Direct communication with Losmandy Gemini frames or AP (via a dedicated serial port) to order them to park without PC intervention (covers the problem of loss of communication).

- Includes a specific output to park Paramount mounts without PC intervention.

- Direct connection to the IP-Switch for the automatic shutdown of the equipment at the end of the session or after a security shutdown.

- Repeated attempt to automatically reconnect the communications port with the PC in the event of loss of communication.

- Automatic search of the communications port at the start of the connection.

- Maximum opening control on a non-parked mount.

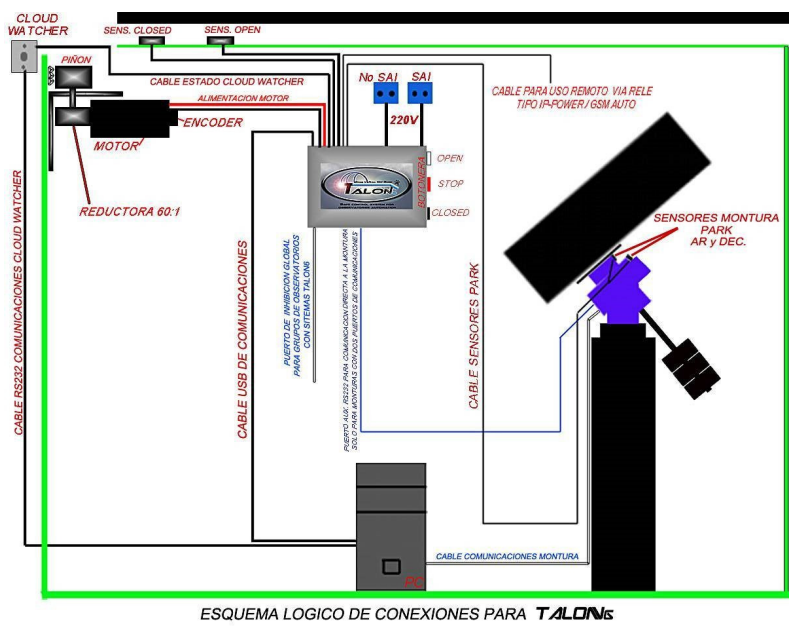

Fig. 4. Logic schematic of the Talon6 connections.

- Manual synchronization of the current roof position.

Basically, TALON6 will park the mount and close the roof when any of the above safety conditions are activated, except (in general) when communications with the PC (PC blocked or shut down) are lost. In this case, the roof will be closed without parking the mount, unless the user sets the system to avoid this closing order (see Figure 4).

There is also a control program that runs on the $\mathrm{PC}$ and communicates with the Talon6 RoR controller in order to allow the user to govern the system and keep them informed of its status. This is what we call the Talon6 RoR driver. This driver is compatible with the ASCOM platform and can be invoked from any automation program such as AutoPilot or CCDCommander, or from image acquisition programs that are compatible with domes or sliding roof observatories such as MaximDL (Figure 5).

\section{FUTURE PLANS}

1. Implement an autonomous energy system based on solar panels and rechargeable batteries, which would enable the use of the observatory and its equipment in the event of a power failure or if direct access to an electrical connection is not available.

2. Place a weather station that would allow us to control the use of the observatory according to the meteorological variables. We aim to incorporate a cloud, wind and solar radiation sensor and a SQM to measure the sky brightness quality.

3. Design a new PROAM Observatory with new materials from recycled plastic, which would facilitate its assembling and transport, with a structural improvement and a lower weight. 


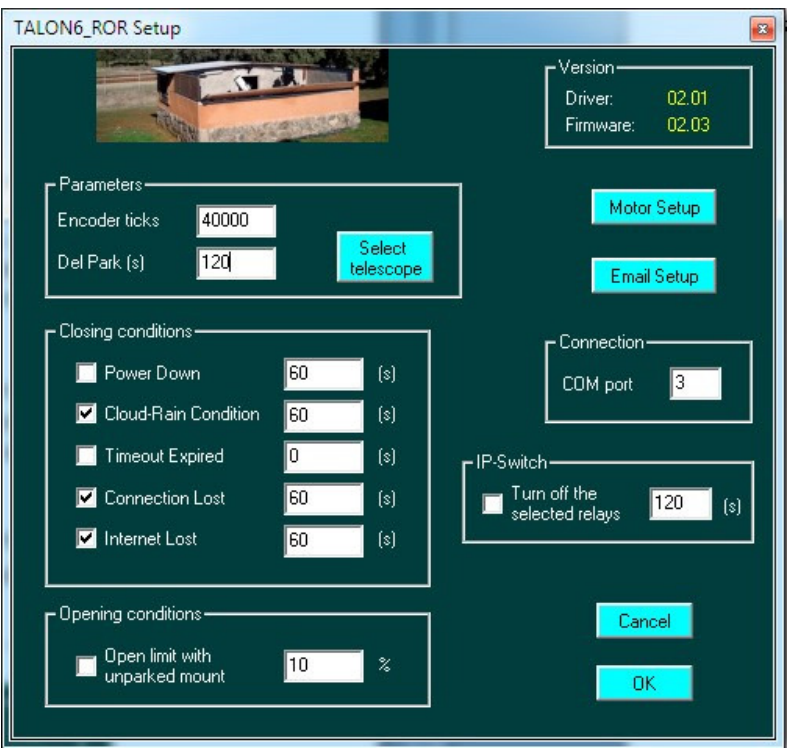

Fig. 5. Setup window.
Acnowledgements: We would like to thank the technical support received by the engineering company ECS, S. L., and Miguel Ángel García Borrella. We also thank the advice of the professor and researcher Alberto Javier Castro-Tirado of the Institute of Astrophysics of Andalusia (CSIC).

\section{REFERENCES}

Castro Tirado, A. J., Jelínek, M., Vítek, S., et al. 2008, SPIE, 7019, 1

Castro-Tirado, A. J. 2010, AdAst, 2010, 68

Castro-Tirado, A. J., Sánchez Moreno, F. M., Pérez del Pulgar, C. J., et al. 2014, RMxAA, 45, 104

Espartero, F. A. 2013, TFM Universidad de Granada, Spain 